\title{
Phylogenetic analysis of the king cobra, Ophiophagus hannah in Thailand based on mitochondrial DNA sequences
}

\author{
Sunutcha Suntrarachun ${ }^{\mathrm{a}}$, Lawan Chanhome ${ }^{\mathrm{a}}$, Montri Sumontha ${ }^{\mathrm{b}}$ \\ ${ }^{a}$ Queen Saovabha Memorial Institute, The Thai Red Cross Society, Bangkok 10330, ${ }^{b}$ Ranong Marine \\ Fisheries Station, Ranong 85000, Thailand
}

\begin{abstract}
Background: Snakes possess adaptive characteristics of morphology that may result in incorrect reconstruction of phylogeny. Molecular approaches have become the major source of new information for advancing our understanding of evolutionary, genetic relationships, and species identification.

Objective: We studied DNA sequences of Ophiophagus hannah in different parts of Thailand and compared them with those of $O$. hannah from other countries.

Materials and Methods: We studied the mitochondrial NADH dehydrogenase subunit 2 (ND2) and control region (CR) sequences of 12 individuals $O$. hannah from different localities across Thailand. Phylogenetic analysis of DNA sequences were compared to the published sequences of $O$. hannah deposited in NCBI GenBank database from other countries.

Results: O. hannah could be categorized into 2 Clades, 5 haplotypes, and 4 localities based on 43 different nucleotide positions from the $736 \mathrm{bp}$ of ND2 and $673 \mathrm{bp}$ of CR. Clade A was haplotype A from southern Thailand. Clade B consisted of haplotypes B, C, D, and E. Haplotype B and C came from northern Thailand. Haplotype D came from western Thailand, while haplotype $\mathrm{E}$ was $O$. hannah from central Thailand. The DNA sequences of Clade B were similar to the sequences of O. hannah in Myanmar and southern China that are already deposited in NCBI GenBank database.

Conclusion: We found a different genotype of $O$. hannah from southern Thailand and suggest that this may be a new species of $O$. hannah.
\end{abstract}

Keywords: CR, ND2, Ophiophagus hannah, phylogenetic

Ophiophagus hannah $(\mathrm{OH})$, known as the king cobra, is the world's largest venomous snake with a length up to 5.8 meters. King cobras feed mainly on other snakes including rat snakes, small pythons, and even other venomous snakes such as various members of the true cobras (genus Naja) and members of the krait family. When food is scarce, they may also feed on small vertebrates, such as lizards, birds, and rodents. O. hannah are distributed across south Asia, southeast Asia, and the southern areas of east Asia (e.g. southern China) where it is not common. They can be found throughout Thailand where the largest known king cobra was caught at Nakhon Si Thammarat in southern Thailand [1]. $O$. hannah likes living in light wooded areas and in

Correspondence to: Sunutcha Suntrarachun, Queen Saovabha Memorial Institute, The Thai Red Cross Society, Bangkok 10330, Thailand.E-mail: sunutcha@yahoo.com open grasslands. However, they can also be found on agricultural land. They often lives near water. They can swim and climb well. They can also move forwards very quickly with an upright head and anterior part of body. King cobras are active at night and during the day. The venom of the king cobra consists primarily of neurotoxins, but it also contains cardiotoxin and some other compounds. Like other venomous creatures, the toxic constituents are mainly proteins and polypeptides [2].

The traditional classification of snakes is based on morphological and histological characteristics [3]. However, snakes possess adaptive characters in various respects of morphology, which may cause misinterpretation of morphological characters to reconstruct incorrect or unresolved phylogeny. Because of this possible confusion, molecular approaches, such as DNA sequencing, have become the major source of new information for advancing 
our understanding of evolutionary and genetic relationships, and species identification $[4,5]$. Comparative sequence analysis is currently used in almost all areas of the biological sciences, including the taxonomic and forensic fields [6]. There are well-recognized advantages for using mitochondrial DNA (mtDNA) sequences for phylogenetic and phylogeographic studies. They offer ease in collecting sequence data because of the compact and conservative gene organization without introns in mitochondrial genes [7-9]. Within mtDNA, some gene sequences are thought to exhibit little intraspecific variability (within members of the same species), but show sufficient interspecific variation (between different species) to allow for an estimation of degrees of relatedness and divergence times via calibrated molecular clocks $[10,11]$.

The present study involves DNA sequences of mtDNA including ND2 and CR for the phylogeographic structure of $O$. hannah in Thailand. The ND2 gene is preferable for examining intraspecific relationships in snakes [12]. CR was also chosen because it is more variable than other regions of the mitochondrial genome. We expected these genes used in conjunction to allow resolution of close as well as more distant relationships within $O$. hannah in Thailand because of their different rates of evolution. Phylogenetic analysis of DNA sequences would also be compared to the published sequences of $O$. hannah deposited in NCBI GenBank database including $O$. hannah from Myanmar and southern China $[13,14]$.

\section{Materials and methods Samples}

Twelve $O$. hannah were obtained from various localities in Thailand. Their shed skins were collected and washed with sterile distilled water, dried in air and cut into small pieces.

\section{Mitochondrial DNA (mtDNA) extraction}

Mitochondrial DNA extraction was performed using $25 \mathrm{mg}$ of each shed snake skin using a genomic DNA extraction kit (tissue) (RBC Bioscience, Beverly, MA, USA). All samples were transferred into a microcentrifuge tubes and $200 \mathrm{ml}$ of GT buffer was added into the tube. A micropestle was used to grind the tissue to a pulp. Proteinase $\mathrm{K}(10 \mathrm{mg} / \mathrm{ml})$ was added to the sample mixture, which was mixed and incubated at $60^{\circ} \mathrm{C}$ for $30 \mathrm{~min}$ to lyse the sample. During incubation, the tube was inverted every $5 \mathrm{~min}$. GB buffer $(200 \mu \mathrm{l})$ was added and vortexed for $5 \mathrm{~s}$ to mix sample and incubated at $70^{\circ} \mathrm{C}$ for $20 \mathrm{~min}$. During incubation, the mixture was inverted every $5 \mathrm{~min}$. Then, absolute ethanol $(200 \mu \mathrm{l})$ was added to the sample lysate, which was immediately vortexed for $10 \mathrm{~s}$. A GD column was placed into a $2 \mathrm{ml}$ collection tube and applied the total mixture to the column. The GD column was centrifuged at 13,000 rpm for $2 \mathrm{~min}$ and the flow through discarded. The GD column was returned to the $2 \mathrm{ml}$ collection tube. W1 buffer $(400 \mu \mathrm{l})$ was added to the column and centrifuged at $13,000 \mathrm{rpm}$ for $30 \mathrm{~s}$. The flow-through was discarded and returned the GD column to the $2 \mathrm{ml}$ collection tube. Wash buffer $(600 \mathrm{ml})$ was added to the column and centrifuged at $13,000 \mathrm{rpm}$ for $30 \mathrm{~s}$. The flowthrough was discarded and the GD column returned to the $2 \mathrm{ml}$ collection tube. The column was centrifuged at 13,000 rpm for $3 \mathrm{~min}$ to dry the column matrix. The GD column was placed into a clean 1.5 microcentrifuge tube. Preheated elution buffer $50 \mu 1$ was added to the center of the column matrix and allowed to stand for 2 min until elution buffer is absorbed by the matrix. The microcentrifuge tube was centrifuged at 13,000 rpm for $30 \mathrm{~s}$ to elute purified DNA.

\section{Oligonucleotide primers and amplification}

CR and ND2 oligonucleotide primers were designed based on NCBI GenBank database (Table 1). DNA amplification using PCR was carried out with 501 reaction buffer containing $10 \times$ buffer, $100 \mathrm{mM}$ each of dNTP, $25 \mathrm{mM} \mathrm{MgCl}, 50 \mathrm{pmol} / \mu \mathrm{l}$ of sense and antisense primers, Taq DNA polymerase, and $10 \mu \mathrm{DNA}$ template. The amplification was conducted on a thermocycle (MWG Biotech, High Point, NC, USA) at $94^{\circ} \mathrm{C}, 3$ minutes, followed by 40 cycles of $94^{\circ} \mathrm{C} / 56^{\circ} \mathrm{C} / 72^{\circ} \mathrm{C}$ one min each with final extension of $72^{\circ} \mathrm{C}$ for $7 \mathrm{~min}$. The final products were electrophoresed on a $1.5 \%$ agarose gel containing ethidium bromide in $1 \times$ TAE buffer along with appropriate molecular size markers. The gel fragment containing the amplified product was excised and extracted using Gel/PCR DNA fragments extraction kit (RBC Bioscience, USA). 
Table 1. ND2 and CR oligonucleotide primers were designed based on the NCBI GenBank nucleotide sequence database. GenBank Accession Nos. for ND2: AY059008.1,AY058997.1 and AY059002.1. GenBank Accession Nos. for CR: NC011394.1, NC010225.1, and NC011393.1.

\begin{tabular}{lll}
\hline Primers & Nucleotides $\left(5^{\prime} \longrightarrow \mathbf{3}^{\prime}\right)$ & Product size (bp) \\
\hline ND2 primers & & 736 \\
ND2-F & 5'-CGGGCAACAGAAGCTGCTAC-3' & \\
ND2-R & 5'-GTCGTAGATAGACGTATAGGCT-3' & \\
Control region & & 673 \\
CR-F & 5'-AGTCTTTATTTCACTATGTA-3' \\
CR-R & 5'-ATAGGGGTTTAAAAAAAGTG-3' & \\
\hline
\end{tabular}

\section{Nucleotide sequencing and phylogenetic analysis}

Sequencing was carried out using the same primers used in the PCRs by first BASE sequencing (Malaysia-http://www.base-asia.com). CR and ND2 DNA sequences from $O$. hannah were aligned using Clustal X and comparison with other O. hannah reported on NCBI GenBank database. Aligned sequences were analyzed using MEGA 4.0 program for the phylogenetic tree (Neighbor-Joining) and genetic distance ( $p$-distance) $[15,16]$.

\section{Results}

A phylogenetic tree (Figure 1) was built from ND2 using Neighbor-Joining (NJ) and separated into 2 Clades; A and B. Clade A consisted of $\mathrm{OH} 1,2,3,4$, 8, 9, and 10, whereas Clade B comprised $\mathrm{OH} 5,6,7$, 11 , and 12 . The polymorphic sites of ND2 were 43 nucleotide positions and 14 nucleotide positions of CR (not shown) among 5 haplotypes and 4 localities (Table 2). Haplotype A contained OH1, 2, 3, 4, 8, 9 , and $10 . \mathrm{OH} 1,9$, and 10 were captive-born snakes, from snake husbandry unit of Queen Saovabha Memorial Institute, whose parents came from southern Thailand. $\mathrm{OH} 2,3,4$, and 8 came from southern Thailand. Haplotype B; OH11 and haplotype C; OH12 came from northern Thailand. Haplotype D; OH5 was from western Thailand. The last haplotype E, OH6 and $\mathrm{OH} 7$, were $\mathrm{O}$. hannah from central Thailand. Genetic distance (Table 3) was calculated by $p$-distance from nucleotide sequences of $736 \mathrm{bp} \mathrm{ND2}$. The range of genetic distance was $0.0000-0.0543$ within O. hannah in Thailand. Phylogenetic analysis and genetic distance of DNA sequences from ND2 were compared to the sequences of $O$. hannah deposited in the NCBI GenBank database including O. hannah from Ayeyarwady Division, Myanmar (Accession No. AY059002) and from Guangzhou,
Guangdong, China (Accession No. NC_011394 and EU921899). Outgroups from neurotoxic and hematotoxic snakes were also included for comparison. The results showed a closer relationship between Clade B of O. hannah distributed in Thailand and O. hannah in Myanmar and southern China than Clade A.

\section{Discussion}

Morphological or histological characteristics alone cannot be used for species identification of species that have adapted the characters of their morphology or altered their visually recognizable features. In this regard, molecular techniques have proven to be an effective tool for reliable species identification, phylogenetics, and biodiversity analysis, and may be the key to successful work in law enforcement and conservation of wildlife $[17,18]$. Phylogenetics and phylogeographic studies of snakes are rare and most have used mitochondrial genes, such as cytochrome c oxidase subunit 1 (CO1), cytochrome b (Cyt b), and NADH dehydrogenase subunit 4 (ND4) $[9,19,20]$. Studies of other vertebrates have often used CR because of its extreme variability [21]. Cyt $b$ has been reported to be a highly conserved region of mtDNA, but a very less intraspecific variation was observed in this region [22].

This study used ND2 and CR to construct phylogenetic relationships of $O$. hannah distributed in Thailand. ND2 is preferable for examining intraspecific relationships in snakes. CR was also chosen because it is more variable than other regions of the mitochondrial genome [12]. However, CR showed less sequence divergence than the ND2. It is possible that ND2 might be better than CR for intraspecific analyses in snake such as $O$. hannah. In particular, levels of sequence divergence were 


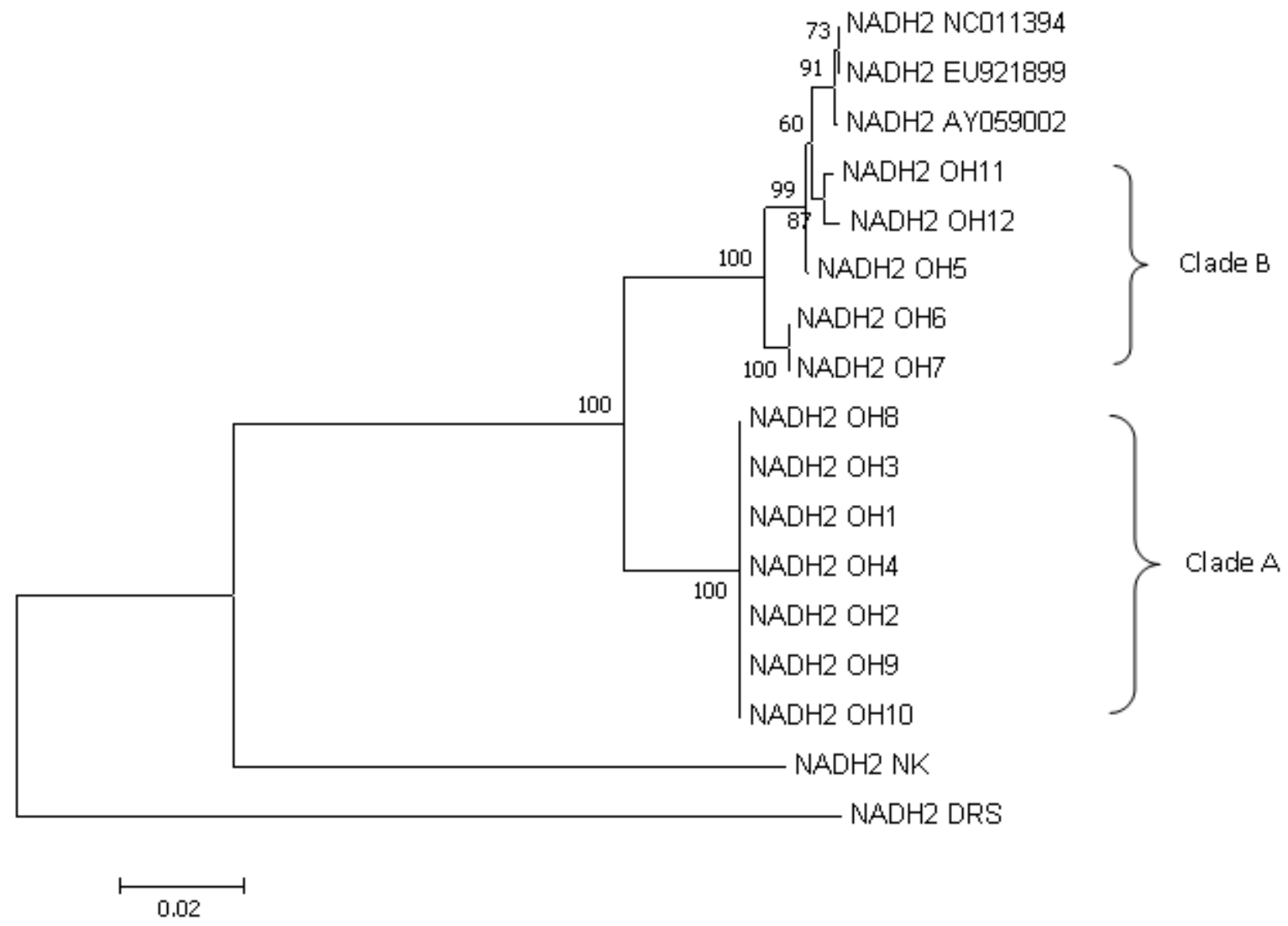

Figure 1. Phylogenetic tree of $12 \mathrm{O}$. hannah was constructed with the Neighbor-Joining (NJ) algorithm. Nucleotide sequences of O. hannah deposited in the NCBI GenBank database consisted of Accession No. NC_011394, EU921899 and AY059002. Accession No. NC_011394 and EU921899 are mitochondrion, complete genome of O. hannah from Guangzhou, Guangdong, China. Accession No. AY059002 is NADH dehydrogenase subunit 2 gene, complete cds from Ayeyarwady Div, Myanmar. Naja kaouthia (NK) and Daboia russellii (DRS) were used as outgroups from neurotoxic and hematotoxic snakes, respectively.

Table 2. Polymorphic site of haplotypes using ND2 indicated nucleotide sequences of each polymorphic site (compared with nucleotide sequences 151-886 from the NCBI GenBank database) started from oligonucleotide primers.

\begin{tabular}{lll}
\hline Haplotypes & $\mathbf{4 3}$ Nucleotide positions & $\begin{array}{c}\text { No. of samples and } \\
\text { localities }\end{array}$ \\
\hline A & A-G-C-T-C-C-C-C-A-A-A-G-A-A-A-C-C-C-A-C-A-C-A-A-T-T-A-C-C-C-T-G-T-A- & 7 (Southern) \\
& G-C-A-A-A-C-C-C-A & \\
B & A-A-T-C-T-T-T-T-G-A-G-A-G-T-T-C-T-A-G-T-G-T-G-T-C-C-G-T-A-G-C-A-C-G- & 1 (Northern) \\
& A-T-C-A-C-T-T-T-G & 1 (Northern) \\
C & G-A-T-C-T-T-T-T-G-G-G-A-G-T-T-C-T-A-G-T-G-T-G-T-C-C-G-T-C-G-C-A-C-G- & \\
& A-T-C-A-C-T-T-T-G & 1 (Western) \\
D & A-A-T-C-T-T-T-C-G-A-G-A-G-T-T-C-T-A-G-T-G-T-G-T-C-C-A-T-C-G-C-A-C-G- & \\
& A-T-C-A-C-T-T-T-G & 2 (Central) \\
E & A-A-T-T-T-T-T-C-G-A-G-A-G-T-T-T-T-A-G-T-A-T-G-T-C-C-A-T-C-A-C-A-C-G- & \\
& G-C-C-G-C-C-T-T-G & \\
\hline
\end{tabular}


Table 3. Genetic distance (p-distance) of ND2 from 12 O. hannah (OH1-OH12) distributed in Thailand compared with $O$. hannah deposited in NCBI GenBank database and outgroups.

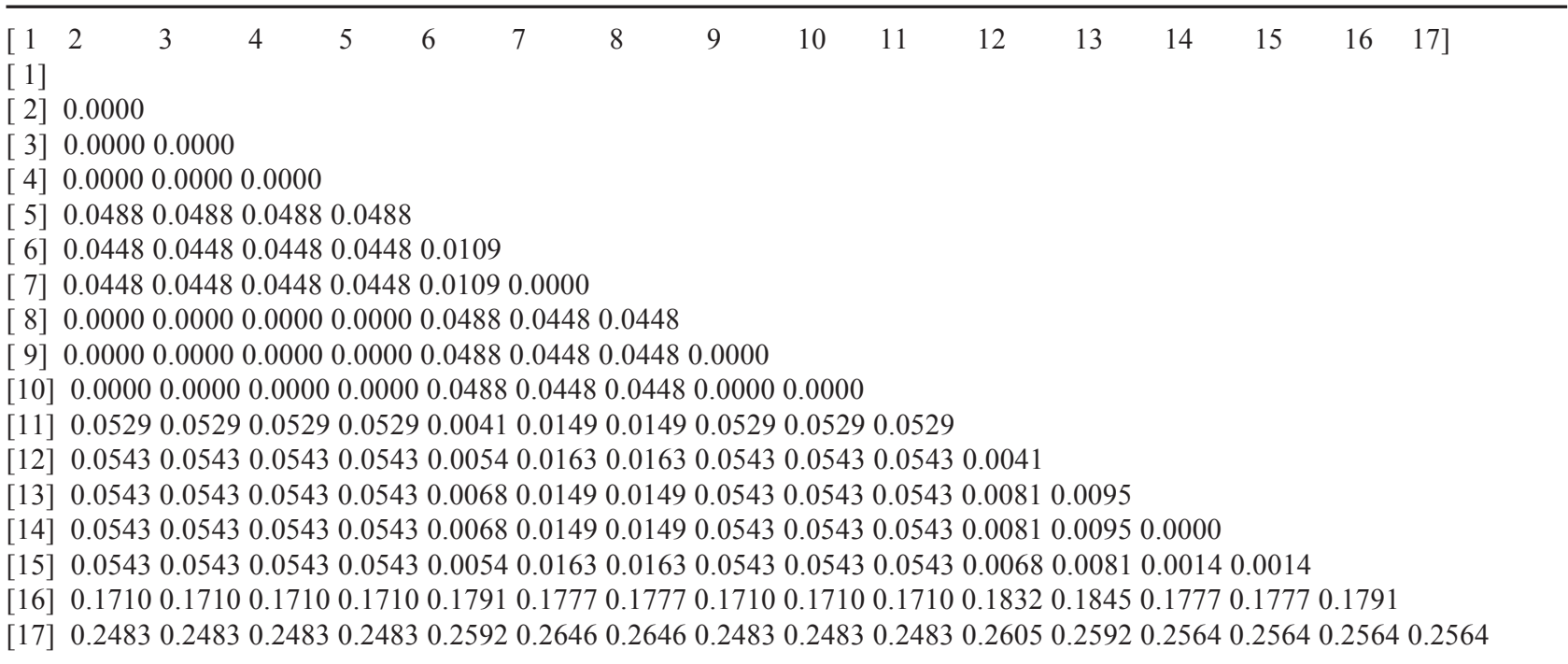

$1=\mathrm{OH} 1,2=\mathrm{OH} 2,3=\mathrm{OH} 3,4=\mathrm{OH} 4,5=\mathrm{OH} 5,6=\mathrm{OH} 6,7=\mathrm{OH} 7,8=\mathrm{OH} 8,9=\mathrm{OH} 9,10=\mathrm{OH} 10,11=\mathrm{OH} 11,12=\mathrm{OH} 12$, $13=\mathrm{NC} 011394,14=\mathrm{EU} 921899,15=\mathrm{AY} 059002,16=$ Naja kaouthia $(\mathrm{AY} 059008)$, and $17=$ Daboia russellii $(\mathrm{NC} 011391)$ as outgroups.

lower for CR relative to ND2 and the number of maximum composite likelihood ( $p$-distance) was less for CR than ND2. The polymorphic sites of ND2 were 43 nucleotide positions and 14 nucleotide positions of CR among 5 haplotypes and 4 localities. A phylogenetic tree based on ND2 could separate $O$. hannah into 2 Clades: A and B. Clade A represented O. hannah from southern Thailand such as Nakhon Si Thammarat and Surattani. Clade B represented $O$. hannah from other parts of Thailand including central Thailand; Bangkok and Samutsakorn, western Thailand; Kanchanaburi, and northern Thailand, Chiang Mai. Clade B suggests the possible geographical origin of regional populations and the short distance migrations from central to western and northern Thailand, respectively. The genetic diversity of Clade B showed high distance among O. hannah that contained 4 different haplotypes. Moreover, it was found that Clade B was more similar to O. hannah in Ayeyarwady Division, Myanmar (Accession No. AY059002) and Guangzhou, Guangdong, China (Accession No. NC_011394 and EU921899) deposited in the NCBI GenBank database than Clade A. It is possible that an additional or different genotype from Clade A in southern Thailand is a new species isolation of Ophiophagus spp. instead of O. hannah [23-25].

In conclusion, the ND2 gene had greater sequence divergence among closely related $O$. hannah than CR. It also may better resolve intraspecific relationships than the $\mathrm{CR}$, which may be useful for inferring interspecific relationships. A phylogenetic tree could separate $O$. hannah in Thailand into 2 Clades. Clade A represented O. hannah from southern Thailand such as Nakhon Si Thammarat and Surattani. Clade B represented $O$. hannah from other parts of Thailand including central Thailand; Bangkok and Samutsakorn, western Thailand; Kanchanaburi, and northern Thailand; Chiang Mai. The genetic diversity of Clade B showed a great distance among $O$. hannah, which similar to the distance between O. hannah in Myanmar and China deposited in the NCBI GenBank database. A different genotype of Clade A from southern Thailand could possibly be a new species isolation of Ophiophagus spp. instead of Ophiophagus hannah.

\section{Acknowledgments}

The authors thank the staff of the Thai Red Cross snake farm for collecting shed snake skins. This work was supported by the Queen Saovabha Memorial Institute, Bangkok, Thailand.

No authors have any conflict of interest to report.

\section{References}

1. Chanhome L, Cox MJ, Wilde H, Jintakoon P, Chaiyabutr 
N, Sitprija V. Venomous snakebite in Thailand. I: Medically important snakes. Mil Med. 1998; 163: 310-7.

2. He YY, Lee WH, Zhang Y. Cloning and purification of $\alpha$-neurotoxins from king cobra (Ophiophagus hannah). Toxicon. 2004; 44:295-303.

3. Wong KL, Wang J, But PPH., Shaw PC.Application of cytochrome b DNA sequences for the authentication of endangered snake species. Forensic Sci Inter. 2004; 139:49-55.

4. Ferri G, Alu M, Corradini B, Licata M, Beduschi G. Species identification through DNA "barcodes". Genet Test Mol Biomarkers. 2009; 13:421-6.

5. Pook CE, McEwing R. Mitochondrial DNA sequences from dried snake venom: a DNA barcoding approach to the identification of venom samples. Toxicon. 2005; 46:711-5.

6. Rastogi G, Dharne MS, Walujkar S, Kumar A, Patole MS, Shouche YS. Species identification and authentication of tissues of animal origin using mitochondrial and nuclear markers. Meat Sci. 2007; 76:666-74.

7. Arif IA, Khan HA, Al Sadoon M, Shobrak M. Limited efficiency of universal mini-barcode primers for DNA amplification from desert reptiles, birds, and mammals. Genet Mol Res. 2011; 10:3559-64.

8. Singh CS, Gaur A, Sreenivas A, Singh L. Species identification from dried snake venom. J Forensic Sci. 2012; 57:826-8.

9. Meusnier I, Singer GAC, Landry J-F, Hickey DA., Hebert PDN, Hajibabaei M. A universal DNA minibarcode for biodiversity analysis. BMC Genomics. 2008; 9:214-7.

10. Khan HA, Arif IA, Al Homaidan AA, Al Farhan AH. Application of $16 \mathrm{~S}$ rRNA, cytochrome $b$ and control region sequences for understanding the phylogenetic relationships in Oryx species. Genet Mol Res. 2008; 7:1392-7.

11. Linacre A, Tobe SS. An overview to the investigative approach to species testing in wildlife forensic science. Investig Genet. 2011; 2:1-9.

12. Ashton KG, de Queiroz A. Molecular systematics of the western rattlesnake, Crotalus viridis (Viperidae), with comments on the utility of the D-loop in phylogenetics studies of snakes. Mol Phylogenet Evol. 2001;21:176-89.

13. Nian C, Xiao-Ping L. Sequencing and analysis of the complete mitochondrial genome of the King Cobra, Ophiophagus hannah (Serpents: Elapidae). Yi Chuan. 2010; 32:719-25.

14. Wuster W, Peppin L, Pook CE, Walker DE. A nesting of vipers: phylogeny and historical biogeography of the Viperidae (Squamata: Serpentes). Mol Phylogenet Evol. 2008; 49:445-59.

15. Lertwatcharasarakul $\mathrm{P}$, Thongtip N, Boonnontae S, Wajjwalku W, Mahasawankul S, Angkawanish T, et al. Haplotypes of Asian elephant (Elephas maximus) in Thailand based on cytochrome $b$ gene. Kamphaengsaen Acad J. 2003; 1:33-9.

16. Tamura K, Dudley J, Nei M, Kumar S. MEGA4: Molecular evolutionary genetics analysis (MEGA) software version 4.0. Mol Biol Evol. 2007; 24:1596-9.

17. Dubey B, Meganathan PR, Haque I. DNA minibarcoding: An approach for forensic identification of some endangered Indian snake species. Forensic Sci. Int. Genet. 2011; 5:181-4.

18. Nicolas V, Schaeffer B, Missoup AD, Kennis J, Colyn $\mathrm{M}$, Denys $\mathrm{C}$, et al. Assessment of three mitochondrial genes (16S, Cytb, CO1) for identifying species in the Praomyini tribe (Rodentia: Muridae). PLoS One. 2012; 7:e36586.

19. Powell RL, Reyes SR, Lannutti DI. Molecular barcoding, DNA from snake venom, and toxinological research: considerations and concerns. Toxicon. 2006; 48:1095-7.

20. Slowinski J, Keogh JS. Phylogenetic relationships of elapid snakes based on cytochrome b mtDNA sequences. Mol Phylogenet Evol. 2000; 15:157-64.

21. Amer SAM, Shobrak M. The efficiency of mitochondrial DNA markers in constructing genetic relationship among Oryx species. Afr J Biotechnol. 2011; 10: 4581-5.

22. Meenakshi K, Suraj T, Bhagwati SS, Sujith VG, Santhoshkumar K, Sanil G. Molecular resolution of four Fejervarya species from western Ghats (India) with their intrageneric phylogeny based on COI, Cyt B, 12S and 16S rRNA genes. Asian J Exp Biol Sci. 2010; 1:782-6.

23. Barker FK, Benesh MK, Vandergon AJ, Lanyon SM. Contrasting evolutionary dynamics and information content of the avian mitochondrial control region and ND2 gene. PLoS One. 2012; 7:e46403.

24. Huang S, He S, Peng Z, Zhao K, Zhao E. Molecular phylogeography of endangered sharp-snouted pitviper (Deinagkistrodon acutus; Reptilia, Viperidae) in Mainland China. Mol Phylogenet Evol. 2007; 44: 942-52.

25. Pyron RA, Burbrink FT, Colli GR, de Oca AN, Vitt LJ, Kuczynski CA, et al. The phylogeny of advanced snakes (Colubroidea), with discovery of a new subfamily and comparison of support methods for likelihood trees. Mol Phylogenet Evol. 2010; 58: 329-42. 